\title{
Non-Syndromic Multiple Supernumerary Premolars - A Report of Two Cases
}

\author{
${ }^{1}$ Dr. P.Aparna M.D.s, ${ }^{2}$ Dr. Shashikala.S M.D.s, ${ }^{3}$ Dr. Sridhar K.R. M.D.S \\ ${ }^{I}$ Consultant Orthodontist \\ ${ }^{2}$ Professor \& Head,Department of Orthodontics, KGFCDS \\ ${ }^{3}$ Consultant Maxillo-facial surgeon
}

\section{Introduction}

Supernumerary teeth or hyperdontia is a common developmental alteration. It may be defined as any teeth or tooth substance in excess when compared to the normal dental formula. ${ }^{1}$ The reported prevalence of this abnormality varies between $0.1 \%-3.8 \%$ in permanent dentition in comparison with $0.3 \%-0.6 \%$ in deciduous dentition. Higher frequency is seen in males than in females. ${ }^{2}$ Supernumerary teeth can occur in the maxilla, mandible or both, but majority are found in the maxilla, $90-98 \%$. Supernumerary premolars are considered as second most common supernumerary tooth after mesiodens. However, their prevalence is quite low in mandibular premolar region, $0.14 \%-0.9 \% .{ }^{3}$ Supernumerary teeth may occur singly or multiple and may be associated with various syndromes and developmental conditions such as cleidocranial dysplasia, Gardners syndrome, and cleft lip and palate. The occurrence of multiple supernumerary teeth without any associated systemic condition or syndrome is a rare phenomenon. These teeth have great potential to disrupt normal occlusal development. Therefore, proper clinical and radiographic examination is important during treatment planning. ${ }^{1}$

The aim of this report is to document two cases of non-syndromic multiple supernumerary premolar teeth in mandible and also associated with supernumerary in anterior part of maxilla.

\section{Case description 1}

A 22 year old healthy male patient reported to Department of Orthodontics, KGF College of Dental Sciences with crowding of teeth. The family, medical and dental history was non-contributory. An intraoral examination showed a Class I molar relationship and crowding in both arches (FIG 1). A complete set of permanent dentition with two supernumerary teeth bilaterally in the mandibular arch was found. These teeth were in lingual relation to first and second premolars. Morphologically, these teeth closely resembled associated premolars, hence, were considered as supplemental. No other supernumerary teeth were found clinically. Patient was advised for panoramic and intraoral periapical radiograghs. Radiographic examination revealed two other supernumerary teeth located in canine region of maxilla. The roots of supernumerary premolar in mandible were complete, while supernumeraries in maxilla were partially completed (FIG 2, 3). Treatment plan of extracting the supernumerary teeth, followed by orthodontic correction for crowding was planned.

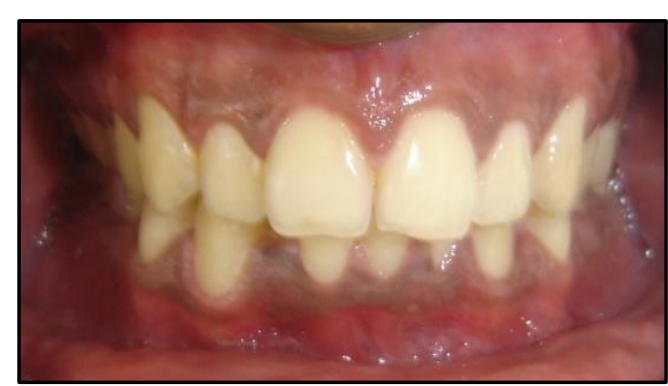

FIG 1: INTRAORAL PHOTOGRAPH SHOWING THE CROWDING IN ARCHES

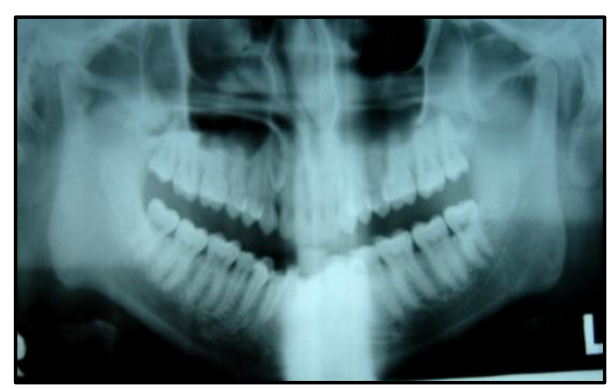

FIG 2: OPG SHOWING THE BILATERAL SUPERNUMERARY MANDIBULAR PREMOLARS \& SUPERNUMERARY TEETH IN MAXILLARY CANINE REGION 

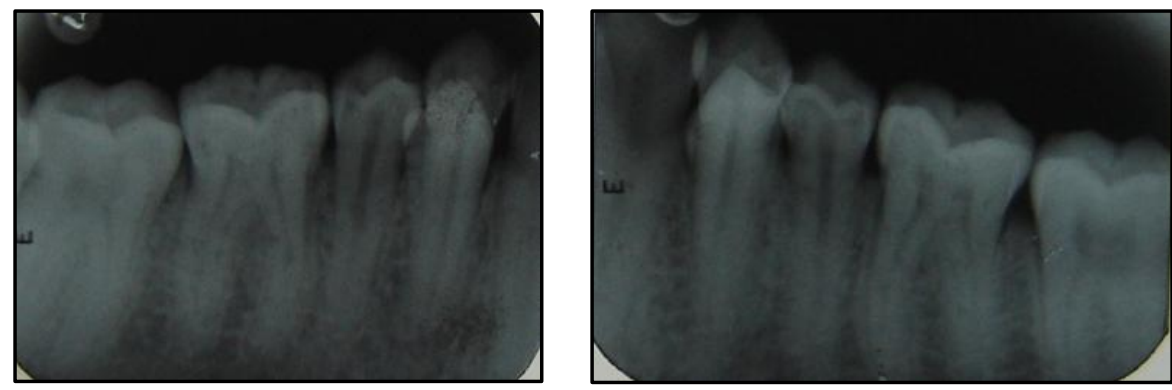

FIG 3: IOPA REPRESENTING COMPLETELY FORMED SUPERNUMERARY MANDIBULAR PREMOLARS

\section{Case description 2}

A 20 year old healthy male patient reported to Department of Orthodontics, KGF College of Dental Sciences for correction of upper front teeth. The family, medical and dental history was non-contributory. An intraoral examination showed a complete set of permanent dentition with mesiodens in maxilla and supernumerary teeth on right side of mandibular arch was found (FIG 4). The mandibular supernumerary tooth was in lingual relation to first and second premolars and resembled premolars morphologically (FIG 5). A class I molar relation was seen. No other supernumerary teeth were found clinically. Patient was advised for panoramic and intraoral periapical radiograghs. Radiographic examination showed the completely formed supernumerary premolar in right side of mandible and mesiodens in maxilla (FIG 6). Treatment plan of extracting the supernumerary teeth, followed by orthodontic treatment was planned.
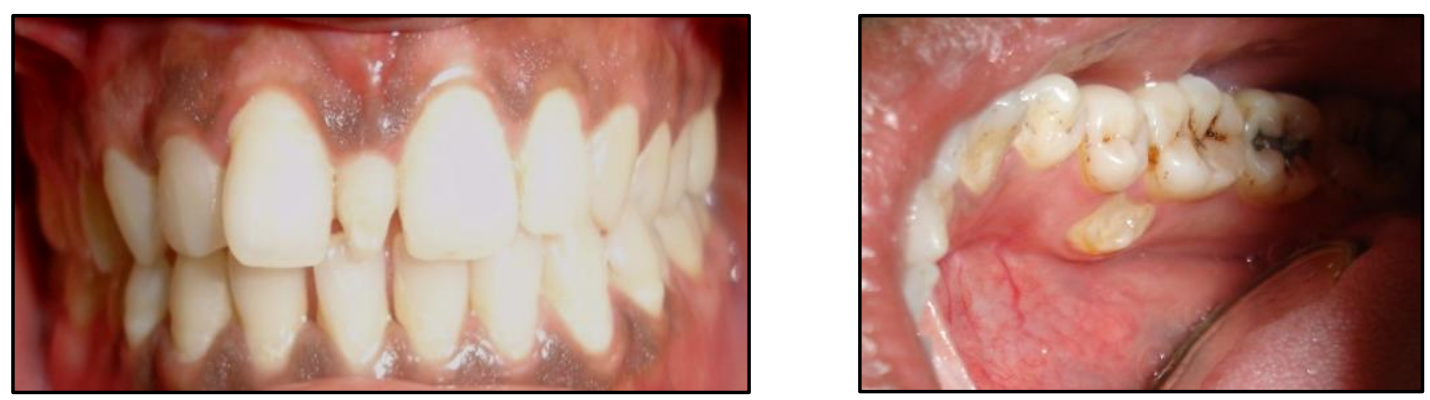

FIG 4: MESIODENS IN MAXILLARY ARCH

FIG 5: LINGUALLY PLACED SUPERNUMERARY MANDIBULAR PREMOLAR ON RIGHT SIDE

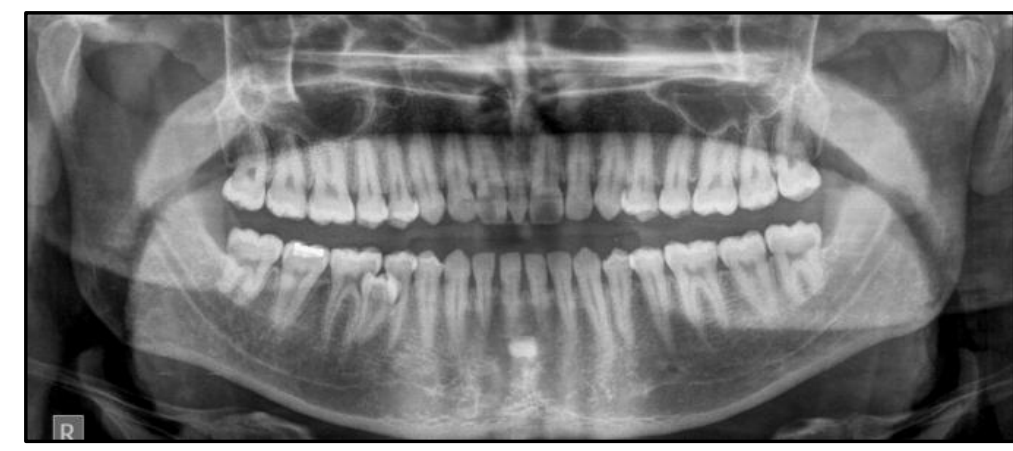

Fig. 6: OPG SHOWING MESIODENS \& UNILATERAL SUPERNUMERARY MANDIBULAR PREMOLAR

\section{Discussion}

The exact etiology of supernumerary teeth is unknown. Several theories have been proposed: proliferation of dental lamina remnants or cell rests, dichotomy theory and a combination of genetic and environmental factors. However, the most accepted theory is hyperactivity of the dental lamina. According to Gardner, late developing supernumerary teeth arise from the proliferation of dental lamina after completion of permanent dentition. ${ }^{4}$ Review of literature confirms that supernumerary teeth have a strong hereditary 
component, without following a simple Mendelian pattern. It also seems that Asian population is more affected with supernumeraries than others. ${ }^{5-8}$

A normal morphological finding of multiple supernumerary teeth in the absence of associated systemic condition or syndrome is rarely encountered. In our two cases, non syndromic occurrence of supernumerary premolars in mandibular arch and supernumerary teeth in anterior maxilla was seen, a rare finding. Both these cases were in post permanent dentition. Sasaki et.al reported bilateral occurrence of supernumerary teeth in maxillary canine and mandibular canine-premolar region. ${ }^{9}$ In 2006 , Hall and Onn presented four cases in which delayed formation and late eruption of supernumerary teeth in the mandible occurred in patients with a history of supernumerary formation in the premaxilla region, which prevented eruption of the associated permanent incisors. $^{10}$

In a study by Hyun et.al, prevalence of non syndromic multiple supernumerary premolar was found to be $0.029 \% .^{5}$ Yusof reviewed cases of non syndrome associated multiple supernumerary teeth and found that mandibular premolar region as most affected site, followed by molar and anterior regions, respectively. ${ }^{11}$ Solares and Romero found that $74 \%$ of supernumerary teeth are located in the mandibular premolar region. ${ }^{2}$

Supernumerary premolars are usually asymptomatic and most cases are diagnosed prior to orthodontic treatment or during routine check up, later. This may be indicative of the late development of supernumerary teeth. The most commonly encountered problems are crowding, separation, impaction or delayed eruption of permanent teeth, rotations, retained deciduous teeth, abnormal eruption sequence, root resorption of adjacent teeth, cystic changes and compromised space closure. ${ }^{11}$

Clinical management of these cases is a great challenge for clinicians. Early diagnosis and treatment of these supernumerary teeth may contribute to an interceptive orthodontic approach and correction of arch crowding. Literature review, recommends surgical removal of these teeth. In contrast, few authors suggest leaving asymptomatic supernumerary premolar in situ, till the completion of permanent dentition. ${ }^{12-14}$ Such cases need close observation with regular radiographic evaluation, which may lead to undue, radiation exposure. Therefore, each case must be considered individually and follow a treatment approach, taking into account the sequelae.

\section{Conclusion}

Multiple supernumerary teeth without any syndromal involvement are uncommon. Early diagnosis and treatment of patients with supernumerary teeth are important. Surgical removal of supernumerary teeth is indicated whenever clinical or radiographic complications are found.

\section{References:}

[1]. Orhan A I, Ozer L, Orhan K.Familial occurrence of non-syndromal multiple supernumerary teeth. Angle Orthod. 2006; 76(5):8917.

[2]. Solares R, Romero MI. Supernumerary premolars: a literature review. Pediatr Dent. 2004; 26(5):450-8.

[3]. O'Dowling, I.B. Supernumerary pre-molar teeth in the mandible. JIDA 2009; 55(6):293-5

[4]. Cochrane S M, Clark J R, Hunt N P. Late developing supernumerary teeth in the mandible. Br J Orthod. 1997; 24: $293-6$.

[5]. Hyun H K, Lee S J et al. Non-syndromic multiple mandibular supernumerary premolars. J Oral Maxillofac Surg. 2008; 66: 13669.

[6]. Scanlan P J, Hodges S J. Supernumerary premolar teeth in siblings. Br J Orthod. 1997; 24: 297-300.

[7]. Martinez-Gonzalez J M, Brinkmann J C B et al. A clinical epidemiologic analysis of a sample of 73 supernumerary premolars. JADA 2010; 141(12): 1435-41.

[8]. Muppa R, Duddu M K, Bhupatiraju P. Non-syndromic supernumerary premolars with striking symmetry - a case report. IJCD 2011; 2(2): 82-4.

[9]. Sasaki H, Funao J, Morinaga H, Nakano K, Ooshima T. Multiple supernumerary teeth in the maxillary canine and mandibular premolar regions: a case in postpermanent dentition. Int J Paediatr Dent. 2007 Jul;17(4):304-8.

[10]. Hall A, Onn A.The development of supernumerary teeth in the mandible in cases with a history of supernumeraries in the premaxillary teeth. J Orthod. 2006; 33: 250-5.

[11]. Yusof WZ. Non-syndromal multiple supernumerary teeth: literature review. J Can Dent Assoc.1990;56:147-9.

[12]. Kaya G S, Yapici G, Omezli M M, Dayi E. Non-syndromic supernumerary premolars. Med Oral Patol Oral Cir Bucal. 2001; 16(4), e522-5.

[13]. Mopager V, Sudha P, Anegundi RT, Kulkarni S, Tavarageri A. Supplemental Premolars in a 13 year old child-A case report. J Indian Soc Pedod Prev Dent. December 2002; 20(4):169-172.

[14]. Mittal M, Sultan A. Clinical management of supernumerary teeth: A report of two cases. J Indian Soc Pedod Prev Dent 2010; 28(3):219-22. 